\title{
EL ESPACIO DE TRABAJO: UNA MIRADA SOBRE LA VIDA COTIDIANA DE LOS MENESTRALES Y ARTISTAS EN LA CÓRDOBA MODERNA
}

\author{
María Ruiz Ortiz \\ Universidad de Córdoba
}

\section{RESUMEN}

El presente trabajo pretende mostrar desde una perspectiva cultural algunos de los aspectos más relevantes de la vida cotidiana de los artesanos andaluces de época moderna, tales como el espacio de trabajo, producción artística, relaciones familiares, venta de productos, educación y aprendizaje.

Palabras Clave: Artesanos, Vida Cotidiana, Educación, Cultura, Edad Moderna, Córdoba

\section{ABSTRACT}

The present article made from a cultural perspective tries to show concrete aspects about the daily life of the Andalusia craftsmen in the modern Age such as the workshops, artistic production, family relationships, product sales, education and learning.

Key Words: Craftsmen, Daily life, Education, Culture, Modern Age, Cordoba

\section{Introducción}

El presente trabajo ofrece una visión cultural sobre un grupo socio-profesional heterogéneo formado tanto por aquellos individuos que desempeñaban oficios mecánicos, como aquellos otros dedicados a la ejecución de artes más nobles, sobresaliendo entre ellas, la pintura, la escultura y la platería.

La principal dificultad con la que se encuentra el historiador para el tratamiento de esta temática es la ausencia de una bibliografía que muestre un enfoque puramente cultural, esto hace que mi investigación se plantee como un reto y ofrezca modestamente una nueva perspectiva histórica, una forma innovadora de mirar al pasado y construir los indicios que marcaban las pautas de conducta en el devenir cotidiano de los artesanos y artistas andaluces durante los siglos XVI, XVII y XVIII. Hasta el momento, la mayoría de títulos arrojan luz sobre aspectos puramente institucionales o meramente 
artísticos, a pesar de ello, contamos con interesantes aportaciones de autores como: Urquízar, Martín González, Villar Movellán, Rubio Lapaz, entre otros.

A lo largo de este trabajo recorreremos diversos aspectos de la vida cotidiana de los oficiales y artistas andaluces que nos ayudarán a entender como construían sus redes de sociabilidad, cómo era percibido su status, cómo se desarrollaba su aprendizaje en los talleres, junto al tratamiento de todos aquellos aspectos materiales y culturales que rodeaban su día a día: espacio de trabajo, producción artística, relaciones intrafamiliares, venta de productos... etc.

Las fuentes de consulta fundamentales para reconstruir su mundo privado son los protocolos notariales, entre los que hay que destacar los siguientes tipos de documentos: testamentos, inventarios, contratos de aprendizajes, cartas de examen y contratos de trabajo. Entre ellas resaltar el especial uso de testamentos e inventarios de bienes, por ser éstos los que más datos ofrecen sobre la cultura material que estuvo a disposición de dicha clase social.

En este sentido hay que apuntar las limitaciones que presentan esta clase de documento.

En primer lugar su escasez cuantitativa pues muchos artesanos y artistas no tenían apenas bienes para testar. Por otro lado, las descripciones que nos ofrecen estos documentos son, en ocasiones, bastantes pobres, lo que limita mucho la labor de reconstrucción de elementos pertenecientes a la esfera cotidiana.

\section{Contexto histórico: Marco estético, cultural y social}

El siglo XVII fue una época de crisis permanente propiciada por distintos elementos tales como: brotes de peste negra, hambrunas, desastres climatológicos; que a su vez condujeron a profundas crisis de subsistencia, elevación continúa de los precios, ingente descenso demográfico. ${ }^{1}$ Andalucía se convirtió así en un reducto de personas cuya única esperanza de vida se basaba en la religión. Esto condujo a una doble actitud: el pesimismo angustioso y desolador o el escapismo sensualista y gozoso de aquellos que no aceptaban la realidad que les rodeaba. Posteriormente, llegado el siglo XVIII hubo una ostensible recuperación de la actividad económica y un ascenso demográfico significativo. Según Ruth Pike, dada la desestimación social del trabajo manual o mecánico, los trabajadores formaban una mayoría casi invisible, una masa homogénea ausente en las fuentes de la época; de ahí que tengamos menos información sobre las clases medias urbanas respecto a otros grupos sociales más estudiados por la historiografía. Durante mucho tiempo las clases privilegiadas ocuparon la mirada y el tiempo de los historiadores, siempre tendentes al análisis de los extremos. Posteriormente hubo un auténtico boom en el estudio de las clases marginales, quedando siempre el estado llano y su diverso abanico de individuos en un segundo plano. Afortunadamente, en los últimos tiempos se han incrementado las investigaciones sobre las clases medias, siendo los mercaderes, los escribanos y los oficios civiles o públicos los más tratados por la historiografía modernista española.

Dependiendo del tamaño de las poblaciones existieron gran cantidad de oficios, los cuales se hallaban divididos, a su vez, en distintas categorías o modalidades. Un ejemplo lo encontramos en la Córdoba del siglo XVI, donde estaban censados ciento cincuenta plateros y orfebres, lo que indica la relevancia de dicho gremio y su labor artística. Entre los sectores artesanales destacaron, en primer lugar, el textil que englobaba a tejedores de seda, lineros, cordoneros, tejedores de paño, pasamaneros, torcedores de seda... Le seguía en importancia el subsector de la piel y del cuero y los oficios artísticos de imaginería, platería y pintura. Por último, debemos hacer alusión a un nutrido sector artesanal, más humilde si cabe, en el que se incluía a zapateros de viejo, zapateros de obra prima, guarnicioneros, odreros, zurradores, albardoneros y guarnicioneros.

Sin embargo, el gremio artístico de mayor relevancia fue y sigue siendo, sin lugar a dudas, la platería. Durante el Antiguo Régimen fue la actividad artesanal más importante en la ciudad de Córdoba, tanto por su número como por su dinamismo y su mayor peso económico; además la platería fue una de las pocas actividades artísticas que traspasaron los límites locales teniendo una proyección provincial. Aunque,

Moreno Alonso, Manuel, Historia de Andalucía, Vol. II, Madrid, 1995, pp. 556-563. 
en el siglo XVII, el número de plateros descendió debido a la situación de crisis generalizada, podemos afirmar que, a finales de dicho periodo, en torno al año 1673 estarían en activo unos ciento cinco o ciento treinta plateros de diversas especialidades destacando entre ellos los plateros de oro y de martillo. ${ }^{2}$

$\mathrm{Al}$ amparo de la Iglesia transformada en indiscutible mecenas y cliente por excelencia se desarrollaron otras actividades artísticas tales como la pintura y la escultura. Debido a la incipiente religiosidad barroca, los templos se llenaron de imágenes, tallas y objetos varios de platería. Este fenómeno impulsó a dichos gremios, dándose un paso del artesanado al arte en sí mismo. Sin embargo, desde una perspectiva institucional, sólo la platería se puede considerar como disciplina artística, pues era la única que contaba con un Colegio o Escuela Oficial en la ciudad de Córdoba.

Respecto a la escultura sólo existieron algunos talleres dispersos e independientes pues las escuelas de imaginería se encontraban ubicadas en las provincias de Granada y Sevilla. ${ }^{3}$ Tampoco existió en la ciudad una escuela de pintores por lo que la mayoría recibieron una formación particular o decidieron marcharse a otras ciudades para llevar a cabo su proceso de aprendizaje, siendo la ciudad de Sevilla la de mayor fama y renombre en el mundo pictórico.

\section{Educación y aprendizaje}

La incursión en el mundo del artesanado comenzaba por el aprendizaje. Éste estaba compuesto por diferentes fases siendo su finalidad la obtención del dominio de un oficio que permitiese al aprendiz llevar a cabo el desempeño correcto de dicho trabajo y poder vivir de él en el futuro. Generalmente, el oficio se transmitía en el seno de la misma familia, lo que daba lugar a auténticas dinastías de plateros, escultores, doradores, pintores... etc.

Esto explica la presencia mínima de contratos de aprendizaje pues entendemos que dicho formalismo legal no sería necesario entre los miembros de una misma familia. Respecto a los contratos de aprendizaje que se nos conservan podemos observar para la ciudad de Córdoba que la mayoría se concertaron con similares características. Éste se efectuaba entre el maestro y el padre del aprendiz que lo formalizaba en nombre de su hijo (menor de edad). Un ejemplo de ello es el contrato temporal fechado el 3 de Octubre de 1609 en el que Martín Alonso de Santaella concierta el aprendizaje de su hijo, Francisco de Santaella, de 13 años de edad con Juan Ortiz, platero de oro, vecino de la collación de San Nicolás de la Villa. ${ }^{4}$

La edad del aprendiz solía oscilar entre los doce y los dieciséis años, aunque hubo casos en los que la edad fue superior.

Los contratos de formación eran temporales y su duración dependía del tipo de oficio, dificultad, destreza y la habilidad del aprendiz para adquirir los conocimientos suficientes para su correcta ejecución. En estos documentos se estipulaban los deberes y obligaciones de ambas partes contratantes; por un lado, los aprendices estaban obligados a residir en el taller y aprender el oficio, por su parte, los maestros debían proporcionarles un buen trato, comida, ropa y cama; a cambio el padre del aprendiz debía pagar al maestro-artesano una compensación por el aprendizaje, ya fuese en dinero o en especie. ${ }^{5}$

Se puede plantear la hipótesis de que la educación fuera de mayor calidad y exigencia cuando se desarrollaba en el seno familiar. Es posible que, en ocasiones, el maestro ocultase información para que el alumno no lo aventajase. Hay que tener en cuenta que, en un futuro, ese mismo alumno se convertiría en maestro y pasaría a ser competencia del que tiempo atrás fuese su preceptor. En este sentido, es interesante el ahínco que muchos tratadistas morales de la época hacían al respecto, buscando siempre el trato correcto y la formación apropiada para dichos aprendices. Este afán normativo es una clara muestra del control que la Iglesia intento ejercer sobre las continuas transgresiones que los maestros artesanos cometían en la impartición de su docencia y el desempeño de su oficio. Una vez transcurrido el tiempo de aprendizaje, que solía oscilar entre los cuatro y seis años, el alumno debía ser examinado para demostrar

\footnotetext{
Valverde Fernández, Francisco, El Colegio-Congregación de Plateros Cordobeses durante la Edad Moderna, Córdoba, 2001, p. 72. Rivas Carmona, Jesús, Puente Genil Monumental, Puente Genil, 1982, pp. 20-21.

Archivo Histórico Provincial de Córdoba (A. H. P. C), oficio22, Tomo 72, (sin foliar).

Martín González, Juan José, El Artista en la Sociedad Española del Siglo XVII, Madrid, 1984, pp. 17-22.
} 
los conocimientos adquiridos en la materia, para lo cual debía pagar previamente unos derechos de examen y mostrar un memorial y certificado de haber aprendido y cumplido el tiempo establecido para el dominio de dicho arte. ${ }^{6}$

Se han conservado algunas cartas de examen que nos ofrecen datos sobre dicha prueba, podemos citar como ejemplo la siguiente carta de examen fechada el 20 de febrero de 1612:

"Carta de Examen de platero de Lorenzo Vázquez, hijo de Francisco Vázquez, notario del Tribunal de cabeza de Rentas en la Santa Iglesia Catedral, verificado ante el prioste de la Cofradía de San Eloy....”?

Esta carta de examen también nos dice quiénes eran las personas que estaban presentes durante el examen, dos alcaldes, dos veedores, dos examinadores y un marcador de la ciudad todos pertenecientes a un mismo gremio. El examen consistía en realizar una pieza y responder a una serie de preguntas teóricas sobre el oficio. Se hacían exámenes de cada especialidad y, una vez superados, se concedía la licencia para obrar y comerciar. Era imprescindible poseer dicha licencia para ejercer el oficio, aunque eran muchas las irregularidades en torno a este tema. Tenemos noticias de muchos fraudes al respecto. En grandes ciudades como Sevilla se registraron varias denuncias a artesanos que llevaban hasta nueve años ejerciendo su oficio ilegalmente sin licencia y que ante una avalancha de quejas, se vieron obligados finalmente a examinarse. Por otro lado, el intrusismo artístico estuvo mirado con lupa, pues dentro de cada categoría artística existían diferentes especialidades y para dedicarse a cada una de ellas había que hacer un examen distinto. En el caso concreto de los plateros se les concedía, tras la correcta finalización de su examen, su propia marca, quedando estampada en una chapa de plata o metal y registrada en el libro de la Congregación. La marca de la ciudad era COR; posteriormente se le añadió la figura de un león rampante hasta finales del siglo XVII. ${ }^{8}$

Las relaciones maestro-aprendiz solían ser cordiales, aunque no faltaron los casos de aprendices que abandonaron el oficio a mitad del aprendizaje e incluso que huyeron de las casas-taller de su maestro. Pero también había ocasiones en las que se estrechaban lazos entre maestro-aprendiz dando lugar a una nueva relación: maestro-discípulo, creándose un vínculo basado en el reconocimiento y admiración por la figura del maestro.

Los lazos de sociabilidad se reforzaban aun más cuando el antiguo discípulo se convierte en miembro de su familia mediante política matrimonial, contrayendo nupcias con una hija del maestro. Esta situación era muy frecuente en la época.

\section{El espacio de trabajo: El taller}

El taller debe ser considerado como algo más que un simple lugar de producción artesanal pues también tenía lugar allí la educación y convivencia de artesanos y aprendices. Los oficios solían discurrir en el ámbito familiar transmitiéndose de padres a hijos/ u otros parientes, aunque en otros casos no había lazos de consanguinidad entre ellos.

Como espacio físico, el taller y la vivienda constituían un mismo lugar. El taller se solía situar en la planta baja, por motivos prácticos, ya que resultaba más cómoda su ubicación en esta parte de la casa. Por ejemplo, en el caso de un taller escultórico por el ruido o el transporte de materiales pesados era más aconsejable que estuviera situado en la planta baja. Además, el taller debía ser un local habilitado y con las condiciones óptimas para la creación artística y la ejecución correcta del oficio. Dentro del taller existían dos espacios diferenciados: el espacio de trabajo propiamente dicho y, junto a él, un espacio para almacenar piezas. ${ }^{9}$

\footnotetext{
6 Valverde Candil, Mercedes; Rodríguez López, María José “La Ciudad de Los Plateros”, Colección Córdoba, Córdoba, 1997, pp. 221-240.

A.H.P.C, Oficio 22, Tomo, 73, (sin foliar)

8 Valverde Candil, Mercedes; Rodríguez López, María José, "La Ciudad de Los Plateros”, Colección Córdoba, Córdoba, 1997, pp. 235-236.

Martín González, Juan José, El artista en la Sociedad Española del siglo XVII, Madrid, 1984, pp.24-49.
} 
Para reconstruir el aspecto de estos talleres artesanales carecemos de testimonios gráficos, lo que dificulta seriamente la labor. Para hacernos una modesta idea sólo contamos con algunos inventarios de bienes que se nos han conservado. Debemos partir de la idea de que los talleres eran lugares poco higiénicos. En el caso de los talleres de pintores eran lugares muy bien iluminados con amplios ventanales. Respecto a su mobiliario era muy sobrio y escaso como observamos en el inventario de bienes del platero Rodrigo de León, fechado en mayo de 1609 o en el inventario de Andrés López Torrico, fallecido el 22 de Agosto de 1621 y formulado por su viuda Inés de Lara.

Ambos son inventarios post-mortem y muestran la sobriedad del mobiliario existente en los talleres. En este último se recogen los siguientes objetos que debieron estar presentes en su taller y que nos ayudarán a imaginar el aspecto de éste, tales como: dos bancos de trabajo, tres sillas, algunos objetos de platería ya elaborados (una custodia y un cáliz sin terminar, entre otros), utillaje de trabajo (punzones y gubias de distintos tamaños), un libro sobre el arte de la platería y un sello o marcador ${ }^{10}$. Los otros objetos nombrados debían pertenecer al mobiliario de la vivienda, aunque éstos eran también escasos, lo que pone de relevancia la humilde condición de vida de dichos plateros y su familia. La presencia de manuales y libros debía ser habitual en aquellos talleres cuyos propietarios no fueran iletrados; aunque la mayoría de artesanos no sabían leer ni escribir. Este dato es palpable en la ausencia de firmas en muchos testamentos de artesanos que vivieron en la Córdoba del Siglo de Oro. También es resaltable la ausencia de retratos u otro tipo de testimonio gráfico sobre los artistas cordobeses existente en la documentación notarial.

Respecto a la ubicación territorial de dichos talleres y tiendas de artesanía, la mayor parte de éstos se encontraban emplazados en las collaciones de Santa María y San Nicolás, con antecedentes ya desde la Edad Media. las tiendas y talleres se solían situar en la franja más meridional de la ciudad:

"Desde la parroquia de San Andrés rectamente a las Tendillas, desde allí a la calle del Duque, desde esta vía a la Pescadería y desde este pasaje rectamente a la iglesia de San Andrés (...)". ${ }^{11}$

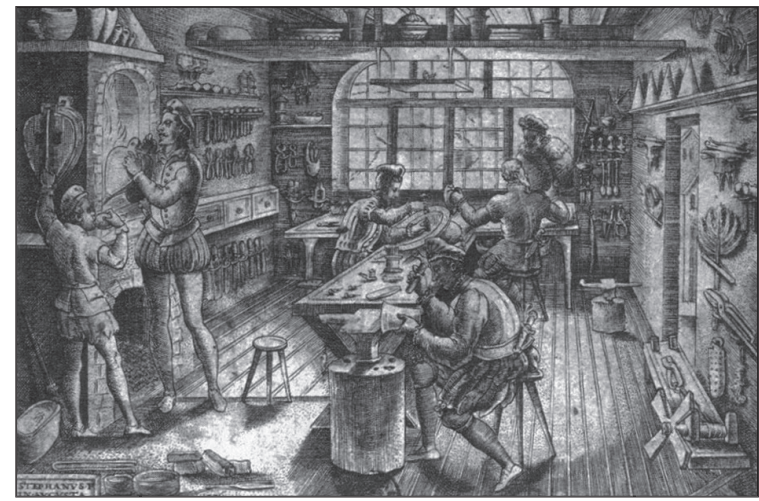

Imagen 1. Interior de un taller de platería. The book of crafts. Grabado

\section{La producción artística: Artistas, obras, tipología y funcionalidad}

Para analizar la producción artística haré, en primer lugar, una distinción clara entre las disciplinas más relevantes del mundo artístico cordobés en época moderna, distinguiendo para ello tres tipos de artes: platería, pintura y escultura. Dentro de la platería, la producción artística fue muy rica y

\footnotetext{
A.H.P.C, Oficio4, Tomo 79, f. 1250r.

11 Valverde Candil, Mercedes; Rodríguez López, María José, “La Ciudad de Los Plateros”, Colección Córdoba, Córdoba, 1997, p. 238.
} 
variada siendo sus técnicas más comunes el cincelado, el torneado, el repujado y las figuras fundidas a la cera (uno de los procedimientos más costosos). Las obras se realizaban con gruesas chapas de plata de diversas calidades siendo la mayoría de piezas de carácter religioso, pues no hay que olvidar que la sociedad andaluza moderna estaba completamente sacralizada. El individuo formaba parte de la Iglesia desde su nacimiento hasta el momento de fallecer. Sin embargo, también hubo una importante demanda civil de piezas elaboradas en metales preciosos, tales como vajillas, candeleros, copas e incluso hasta sillas de montar a caballo se hicieron con dicho metal precioso. ${ }^{12}$

A pesar de ello la mayor parte de la producción fue ordenada hacer por y para la Iglesia. Entre los objetos más frecuentes estaban las cruces procesionales, porta-paces, acetres, cajas de formas, cálices y las custodias. Estas últimas adquirieron gran importancia por el creciente protagonismo que la Iglesia Católica concedió a los sacramentos en un momento crucial en la lucha contra la herejía protestante. En el siglo XVII, la actividad platera descendió notablemente en Córdoba, al mismo tiempo que la calidad de la materia prima empleada. Pocas figuras sobresalieron en estas fechas en el panorama orfebre en el que la mayoría de las veces los artistas no estampaban su punzón en las obras, por lo que muchas piezas se presentan anónimas. Este fenómeno se extiende a otras disciplinas artísticas como la escultura y la pintura. Sin embargo conocemos los nombres de algunos plateros destacados de este siglo, tales como: Pedro de Bares, Diego de León, Simón Pérez de Tapias y Juan Palomo Cuellar. Las obras artísticas gozaban de un triple valor: artístico, material y fervoroso (éste último fue esencial como eje adoctrinador de masas). En las estimaciones de las obras de platería y orfebrería figuraban dos elementos: el peso del material y la hechura. ${ }^{13}$ Además se reivindicaba que la obra fuese valorada más por su valor artístico que por el material.

Dentro de la pintura existió una gran gama de modalidades como la pintura al temple, el óleo, la iluminación, el estofado...etc. Hubo dos tipos de pintores fundamentales: el pintor de guadamecíes y el pintor de imaginería. Entre las obras más demandadas estaban los guadamecíes, retablos y lienzos de temática religiosa. Durante el siglo XVI trabajó en Córdoba un número elevado de pintores, la mayoría de ellos sólo conocidos por la documentación notarial, pues la producción historiográfica

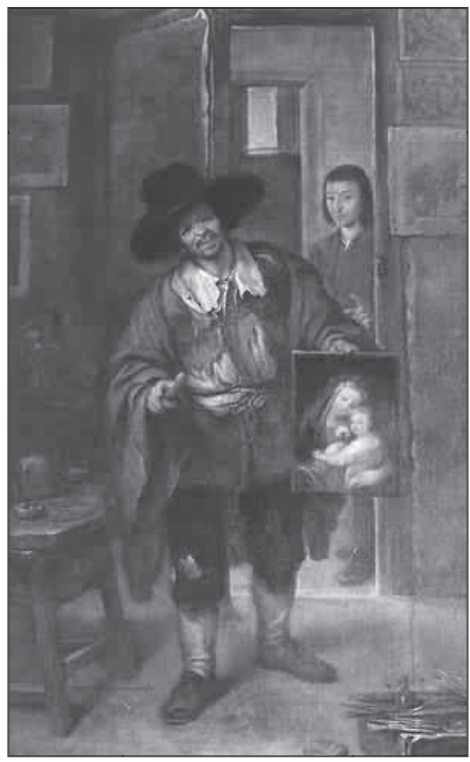

Imagen 2. "El pintor pobre" de José de Antolinez.

2 AAVV, Colección de Córdoba, Vol. II, Córdoba, 1997, pp. 230-234.

13 Martín González, Juan José, El Artista en la Sociedad Española del S. XVII, Madrid, 1984, pp.102-105. 
no los menciona en absoluto. Aunque la calidad de sus obras pictóricas fue menor, estos pintores constituyeron el baluarte del nivel medio de la pintura cordobesa de la época.

Entre ellos debemos mencionar a: Bartolomé Ruiz, Antón Pérez, Pedro Portillo, Luís Fernández; Francisco del Rosal. De ellos y de muchos otros sólo conocemos su nombre y alguna de sus obras. ${ }^{14}$

La práctica de la escultura en rigor se refiere a dos técnicas: el modelado y la talla. La madera más empleada fue el nogal y la temática principal la escultura procesional. El arte de la escultura que más sobresalió fue, sin lugar a dudas, la imaginería. Esta especialidad estuvo reservada a muy pocos artistas pues no se trataba simplemente de hacer esculturas para rezar, sino que debían esculpir obras con verdadero poder evocador y fervoroso que movieran y guiasen el alma cristiana. ${ }^{15}$ Los textos sagrados, hagiografías y devocionarios debieron ser instrumentos de trabajo imprescindibles en un taller de escultura barroca. Ya comenté con anterioridad que no existió una escuela escultórica en Córdoba, por lo que la mayoría de escultores cordobeses se formaron en las escuelas sevillanas y granadinas. Todos estos artistas se hallaban inmersos en una sociedad confesionalmente católica y sus encargos procedieron de organismos ligados directa o indirectamente con la vida religiosa.

\section{TIPOS DE ARTESANOS}

1. AGRICULTURA: aladreros, albardoneros, arneros, atraeros, dedaceros, esparteros, freneros, herreros, herradores, poceros y regueros.

2. ALIMENTACIÓN: boteros, caldereros, canasteros, certeros, cuchilleros, espitaleros, odreros, oficiales de lo pardo y de lo verde, olleros, palilleros, tinajeros, vidriaderos y vidrieros.

3. VIDA Y AJUAR DOMÉSTICO: adobadores de sillas, boteros, caldereros, canasteros, carpinteros, cereros, cerrajeros, cesteros, cordoneros, cuchilleros, curtidores, escoberos, esparteros, espitaleros, heneros, jaboneros, maestros de molino, molineros, odreros, oficiales del barro, oficiales de lo pardo, de lo verde, olleros, palilleros, silleros, tejedores, tinajeros, tintoreros, torneros, veleros, vidriaderos y vidrieros.

4. VESTIDOSYADORNOS: alpargateros, bataneros, boneteros, bordadores, botoneros, calceteros, cardadores, cinteros, coleteros, cordoneros, curtidores, chapineros, guanteros, lenceros, oficiales de la carda, oficiales de tafetán, oficiales de zapatería, pasamaneros, plateros, sastres, sederos, sombrereros, tejedores, tintoreros, togueros, torcedores de seda, tundidores y zapateros (en todas sus modalidades).

5. CONSTRUCCIÓN: alamines, albañiles, aserradores, canteros, carpinteros, cerrajeros, empedradores, herreros, labrantes, madereros, maestros de madera, oficiales del barro, peones de albañilería, poceros, riperos, tejeros y yeseros.

6. MANIFESTACIONES ARTÍSTICAS: alamines, albañiles, alfareros, bordadores, canteros, carpinteros, cerrajeros, entalladores, escritores de libros, escultores, guitarreros, herreros, organistas, pintores, plateros, sochantres, violeros, torneros y tejedores.

7. OTROS ÁMBITOS: alcabuceros, ballesteros, espaderos y fundidores.

Cuadro I. Clasificación trabajos artesanos.

\footnotetext{
14 Urquízar Herrera, Antonio, Historiadores y Pintores: Historia de la Historiografía de la Pintura del S. XVI en Córdoba, Córdoba, 1999, pp. 95-99.

15 Villar Movellán, Alberto, Las Escuelas del Barroco y la Imaginería de Puente Genil, serie azul, Córdoba, 1989, pp. 17-18.
} 


\section{Venta y contratación de obras}

Los objetos artísticos eran demandados por clientela corporativa e individual tanto de carácter civil como religiosa, siendo continúa la demanda artística entre la burguesía, las clases nobiliarias y la Iglesia, convirtiéndose esta última en la principal consumidora de arte. La liturgia cristiana, necesitaba numerosos objetos de culto para que la Iglesia enriqueciera los templos y conventos que se iban levantando en la ciudad de Córdoba y en el resto de provincias andaluzas. Con el paso del tiempo, el valor del arte subió, aunque el material empleado fuese de baja calidad. Por la documentación existente podemos observar que las tasaciones eran cada vez mayores. Por un lado, crece el precio de las obras y, por otro, los artistas rechazan el pago de impuestos o alcabalas. Un ejemplo ilustrativo es el de los plateros, éstos pagaban por el metal, no por la hechura; argumento que van a esgrimir hasta la saciedad los pintores, pues, según éstos, lo decisivo en una pintura es su propia realización y no los materiales empleados. ${ }^{16}$

Aunque los artistas siempre defendieron que lo suyo era "un arte liberal" y no una actividad de simple compra-venta, la realidad demuestra que algunas veces si fue así. Todos ellos plateros, pintores y escultores trabajaban junto a mercaderes que se encargaban de distribuir sus piezas en las ferias de otras capitales y pueblos. La difusión de las piezas cordobesas, más que por encargo directo a los talleres, se realizó mediante esta modalidad en la que la figura principal era el corredor. Sin embargo, también hubo muchos encargos directos de carácter civil y religioso como demuestra la documentación notarial. Un ejemplo de encargo civil se puede observar en la escritura otorgada por Juan Casa, platero de mazonería, en el año 1608, obligándose con Bartolomé Cerón a elaborarle los siguientes objetos: dos cantimploras pequeñas, dos salvillas, dos candeleros de mecheros y seis escudillas. ${ }^{17}$

Otro tipo de contrato directo es aquel en el que se requería el trabajo del menestral durante un tiempo establecido, ejerciendo la labor en la vivienda del propio contratante. Esta modalidad es menos frecuente, pero podemos citar un ejemplo en la pintura. En 1632, el oficial pintor de imaginería, Damián de Torres fue contratado por Bernabé Sánchez, carpintero, para acudir a su casa a pintar imágenes durante un año y con el salario de cuatro reales diarios y la comida. ${ }^{18}$ De esto se deduce que también las clases medias urbanas eran demandantes y consumidoras de arte, aunque en menor medida que las clases privilegiadas. A pesar de ello, las instituciones religiosas fueron las principales compradoras de arte y así lo atestigua la documentación. Como ejemplo, podemos citar la escritura otorgada en noviembre de 1610 por el platero Pedro Sánchez de Luque con el presbítero de la Iglesia de Pedroche, en la que se compromete a hacerle una custodia, un cetro y un cáliz. Como este caso encontramos numerosos y similares ejemplos en la documentación notarial. La platería ocupó un lugar de especial relevancia en la compra-venta de objetos artísticos. El apogeo de ésta en los siglos XVI-XVII se cimentó en dos pilares básicos: los bajos precios y una amplia red de distribución.

Muchos talleres dependían directamente del trabajo que les proporcionaban los comerciantes y feriantes acomodados para los que trabajaban. Evidentemente, los corredores y feriantes trabajaron con aquellos talleres que ofreciendo obras de calidad, cobraran más barato por trabajar los metales preciosos. Desde el siglo XVI, la mayoría de plateros cordobeses se surtieron de un mismo depósito de este rico metal ubicado en una vivienda de la calle de La Plata, una de las afluentes a las Tendillas. Los comerciantes se encargaban tanto de vender los objetos manufacturados como de comprar los metales preciosos, siendo muy frecuente la compra de metales usados, pues eran más baratos que los nuevos. Además ya comenté con anterioridad que la calidad y precio de los metales preciosos descendieron notablemente ante la crisis generalizada del siglo XVII. En la documentación se observa como la escasez de medios hacía que las obras no fueran todo lo suntuosas que deberían ser en esencia. Los feriantes cordobeses ampliaron mercados y establecieron una red de distribución de objetos de platería a nivel nacional. Su lugar de trabajo era el "escriptorio" (una especie de oficina comercial), escenario de venta de objetos artísticos de la ciudad. Solía estar situada en la planta baja de la casa y poseía dos puertas,

\footnotetext{
Martín González, Juan José, El artista en la Sociedad Española del S. XVII, 1984, Madrid, pp. 195-214.

A. H .P.C, Oficio 4, Tomo 53, F. 748-749.

A. H. P. C, Oficio 4, Tomo 91, F. 478.
} 
una que comunicaba con la vivienda y otra con la calle. En ellos los comerciantes guardaban toda la documentación relacionada con su negocio: libros de caja, cartas, cuentas, contratos, estipulaciones de viajes. ${ }^{19}$ Allí trataban con los clientes, acudían los maestros de taller a concertar obras y, en resumen, se producía toda la actividad de venta; además aquellos lugares debían ser auténticos depósitos de metales preciosos y, por esto, muchos maestros plateros acudían a ellos para abastecerse de oro y plata. Estos plateros-comerciantes constituyeron un $10 \%$ de la población con altos ingresos, que serían el germen de la futura burguesía.

La demanda de arte estuvo impulsada por dos motivaciones: el interés artístico y la devoción religiosa. Esto produjo un aumento en los encargos y promovió el bienestar del artesanado y de los artistas cordobeses.

La demanda civil estuvo enfocada a la búsqueda del prestigio social por parte de los clientes y mecenas; mientras que la demanda religiosa sirvió para cubrir las necesidades del culto en un periodo envuelto por la fe cristiana.

\section{Percepción y representación social: los oficios mecánicos y el arte. De los márgenes de la pobreza al elevado bienestar}

"Nadie me cree cuando afirmo que no ejecuto trabajo vil, pues no soy pintor, no tengo taller, ni pinto por negocio; yo me enfrento al lienzo por placer propio y regio. No soy un simple artesano de los pinceles".

Diego Rodríguez de Silva y Velázquez.

Hablar de artesanos y artistas como grupo social insertado en el estado llano o tercer estado implica tratar una diversidad de estilos de vida, algunos gozosos de bienestar social y otros carentes hasta de las necesidades más primarias, así dan testimonio los inventarios de bienes, cartas de dotes y testamentos que se han conservado. Estos documentos nos sirven para reconstruir el estilo de vida de estos artesanos y artistas a través del estudio de su cultura material. Como ejemplo, podemos la carta de dote del latero cordobés, Francisco de Ayala, cuya transcripción ofrezco a continuación ${ }^{20}$ :

"Sepan cuantos por esta carta vieren como Francisco de Ayala, latero y vecino de esta ciudad de Córdoba en la collación de Santa María, hijo legítimo de Juan de Ayala y Ana Pérez, difunta natural y los dichos míos padres de esta ciudad de Córdoba (...) Otorgo y conozco que recibo esta dote caudal y casamiento con Doña Antonia Bravo (...)//los siguientes bienes y precios que de ello es como se sigue:

- Una milla de escarlatilla con guarnición de plata.

- Una camisa con mangas de bretaña encinta.

- Dos sábanas, una con puntas.

- Dos almohadas de cree ancha con su henchimiento.

- Una colcha colorada con su besapies de lo mesmo con guarnición de lata.

- Un colchón listado con su henchimiento

- Otro colchón blanco con su henchimiento de lana.

- Una cama de madera de nogal

- Un velador

- Una tabla de manteles.

- Seis biazas.*(alforjas de cuero).

- Un bufete de nogal

- Cuatro sillas de banqueta de moscobia

19 Valverde Fernández, Francisco, El Colegio-Congregación de Plateros de Córdoba, pp. 417-421.

20. AHPCO, Protocolos Notariales, año 1672, Oficio 4, Leg.726, (sin foliar): Carta de Dote. 
- Una docena de platos y escudillas.

- Una toalla.

- Unas enaguas blancas

- Un bancal

- Unas calcetas blancas de lino

- Unas medias de seda de color

- Una almilla blanca.*( especie de jubón cerrado, ajustado al cuerpo)

- Una estera de juncos.

- Una sartén

- Un cuchillo de mesa.

Hay que partir de la premisa de que no constituían un grupo homogéneo y su principal vinculación era la ejecución de un trabajo mecánico o vil. Éstos se agrupaban en gremios marcados por una fuerte jerarquización. Según el tamaño de las poblaciones existía gran cantidad de oficios y éstos a su vez se hallaban divididos en distintas categorías o modalidades. Los gremios estaban sometidos al gobierno municipal. No cabe duda que el sector artesanal fue uno de los que experimentó con mayor rigor las calamidades del siglo XVII hambre, peste, inflación, la desatada tributación y el servicio de armas. ${ }^{21}$

En términos generales se puede intuir que la diferenciación profesional tenía equivalencia a efectos fiscales, como algunos oficios que, por ser minoritarios, escapaban del control de los gremios, pagaban menos y tenían un nivel inferior de cualificación profesional. ${ }^{22}$ Las fuentes indican para el caso de Andalucía que la mayoría de artesanos y artistas no sobresalían económicamente de la generalidad de los vecinos del común excepto una cierta elite artesanal minoritaria de la que hablaremos con posterioridad.

Los salarios oscilaban entre los cuatro reales que cobraban los herreros hasta los ocho que percibían pintores y plateros maestros; los oficiales entre tres y seis reales y los aprendices una media de un real y medio aproximadamente.

Sus testamentos y cartas de dotes muestran como su situación socio-económica fue tan variopinta como lo era la sociedad a la que pertenecían. Algunos disfrutaron de un significativo patrimonio, otros se situaban en la normalidad y muchos otros llegaban a rozar los límites de la miseria. ${ }^{23}$ La modesta condición de la mayoría de artesanos y artistas cordobeses del Siglo de Oro hizo que muchos de éstos compaginaran la actividad artística con otras labores, tales como, el cobro de determinados impuestos. Por ejemplo, el pintor cordobés Andrés Fernández tuvo a su cargo la cobranza de la renta del pan de tenderos, mesoneros y molineros durante el año $1609 .{ }^{24}$

Otro caso fue el del pintor Francisco de Oliver que tuvo a su cargo el cobro y administración del estanco de los naipes en la ciudad de Córdoba en 1610.

¿Cómo eran percibidos por sus coetáneos? Parece que no hubo una separación clara del trabajo gremial y artístico, salvo en casos muy excepcionales y artes concretas tales como la pintura, la platería y la escultura, consideradas más nobles. Sin embargo, muchos de ellos buscaron el prestigio social.

Pocos artistas andaluces lucharon tanto como los plateros cordobeses para dignificar su función, valorando la condición de arte liberal. Su arte estaba unido a la suntuosidad que implica el uso de metales preciosos como material de trabajo. Sin embargo, ellos siempre reafirmaron que el verdadero valor de sus obras era el artístico y no el valor de la materia empleada. ${ }^{25}$

Este intento de emulación de las elites estará patente en varios aspectos. Por un lado, los artistas se negaran al pago de impuestos o alcabalas. Consideraban que su "status" no era servil. Ellos no ejecutaban un simple oficio mecánico, sino que hacían arte. Por otro lado, la exención de impuestos era un símbolo ligado a las clases más nobles.

21 Domínguez Ortiz, Antonio, "Economía y Sociedad en la Córdoba del siglo XVII", Córdoba. Apuntes para su Historia, AAVV, Córdoba, 1981, pp.11-20.

22 Pla, LLüisa; Serrano, Ángels, La Societat de LLeida Al Set-Cents, Lleida, 1995, pp. 80-99.

23 Almagro García, Antonio, Artistas y Artesanos en la ciudad de Úbeda durante el siglo XVII, Jaén, 2003, pp. 61-69

24 Archivo Histórico Provincial de Córdoba, A. H. P. C, Protocolos Notariales, Córdoba, 1609, Oficio 4, Tomo 57, F. $32-33$ v.

25 Martín González, Juan José, El Artista en la Sociedad Española del S. XVII, Madrid 1984, pp. 102-105. 
Otro de los factores presentes en este intento de dignificación por parte de los plateros cordobeses fue el requisito de entrada en el gremio: "La limpieza de sangre".Se desconoce el inicio de esta práctica como método de regulación de acceso de individuos al Gremio de San Eloy. Los primeros expedientes de sangre arrancan del año 1729 y parece que la práctica fue abandonada allá por el año 1832. El procedimiento era el siguiente: Los aspirantes a plateros debían rellenar un cuestionario al que debían contestar tres o cuatro testigos, para conocer la limpieza de sus antepasados y cumplía con una serie de requisitos estipulados:

"Si era hijo de padres honrados, cristianos viejos, limpios de toda mala raza, que no tengan ni hayan tenido oficios mecánicos y que no estén públicamente notados de vileza alguna".

De esta forma los maestros plateros y el gremio en sí debían sentirse como un estamento superior, no permitiendo la entrada a individuos que pudieran poner en tela de juicio la nobleza de su profesión. Este comportamiento se extrapola perfectamente a lo que estaba sucediendo a nivel nacional con los artistas de mayor relevancia. En este sentido debemos recordar que muchos se interesaban por la hidalguía y sentían un enorme aprecio por las órdenes militares.

Estas manifestaciones cotidianas expresaban una "nobleza de actitud" de los plateros cordobeses y, en general, de muchos artistas en la España Moderna.

Otro fenómeno habitual fue el uso del título de "maestro" por parte de los oficiales por razones económicas (mayores salarios) y por prestigio social.

A pesar de sus esfuerzos, se encontraban insertos en una sociedad regida por la moral burguesa y, el estilo de vida nobiliario imponía sus propias reglas.

Un ejemplo de ello fue la pragmática del ocho de marzo de 1674 en la que se ordenó que sólo pudiera usar coches, carrozas, estufas, calesas y forlones los estamentos privilegiados, quedando excluidos los plateros, maestros de obras, y oficiales so pena que le sean requisados... ${ }^{26}$.

Los oficios mecánicos eran rechazados socialmente y considerados viles pues trabajaban directamente con sus manos. Erasmo de Rótterdam decía en su Elogio de la Locura:

"Hablemos ahora de las artes. ¿Qué es sino la sed de gloria le induce a los mortales a cultivar estas disciplinas, reputadas como excelsas y a transmitir a la posteridad el fruto de sus trabajos? De tantos desvelos, de tantos sudores, se creyeron resarcidos algunos hombres verdaderamente necios, alcanzando no sé que fama, que es lo más vano que puede existir. No obstante, a esta locura debéis una las mayores y más dulces ventajas de la vida, como es sacar partida de la locura de los demás”27

Por su parte, los artesanos adoptaban comportamientos y actitudes emuladoras de los hidalgos en el vestir, en las formas y en el propio concepto de trabajo. Observamos las diferencias entre los tres planos de representación de los artesanos, entre su status real, su propia concepción e intento de emulación de un status superior y la percepción vil que de ellos tenía el resto de la sociedad. siguiente manera:

El viajero francés Joly visitó España durante su Siglo de Oro refiriéndose a los artesanos de la

"Sólo trabajaban lo justo para salir del paso y la mayor parte del tiempo están desdeñosamente sentados cerca de su tienda y desde las dos o las tres de la tarde se pasean espada al cinto; ya no hay razón para que hagan nada hasta que habiéndolo gastado todo, vuelvan a trabajar". ${ }^{28}$

\footnotetext{
26 Véase: Reder Gadow, Marion, "Transformación Social. Cambio Mental en las postrimerías del siglo XVII”, Congreso sobre la Andalucía de Finales del Siglo XVII, Ayuntamiento de Cabra, Cabra, 1999, p.226. Nota: Dicha medida pretendía controlar los gastos durante la crisis del siglo XVII y también marcaba las diferencias sociales.

27 Rótterdam, Erasmo, Elogio de la Locura, Cátedra, Madrid, 1999, p.36.

28 Calvo, José, Así Vivían en el Siglo de Oro, Anaya, Madrid, 1989, pp. 58-68.
} 
Entre el artesanado cuando la necesidad no obligaba era costumbre sentarse al sol con otros muchos y discutir sobre cualquier cosa, ocupando un lugar preferente las cuestiones de estado. Un testimonio de la época cuenta:

"A menudo riñen sobre eso, alguno que se cree mucho mayor político que los demás pretende que se sometan a su opinión y otros, tan tercos como él no quieren hacerlo de suerte que se baten sin cuartel..."

No cabe duda que el testimonio del viajero extranjero es demasiado subjetivo pues aunque es cierto que muchos holgaran más de la cuenta, la mayoría de ellos trabajaban para sobrevivir y poder hacer frente a las posibles complicaciones que se presentasen (el siglo XVII estuvo plagado de muchas de esas vicisitudes, pestes, hambrunas, inflación.....). ${ }^{29}$

Finalmente debemos hacer alusión a esa minoría privilegiada dentro del sector artesanal perteneciente a los oficios artístico-artesanos dotados de mayor nobleza como fueron la escultura, la pintura y la platería. ${ }^{30}$

A continuación haré mención a casos singulares de artistas-artesanos cordobeses del mundo de la pintura, la escultura y la platería respectivamente. El primero de ellos fue el pintor Pablo de Céspedes. ${ }^{31}$ Su caso es paradigmático, pues a pesar de su elevada situación socio-económica, vivía de forma miserable. A su muerte dejó una casa llena de gemas, porcelanas, antigüedades, astrolabios, relojes, lienzos y una biblioteca compuesta por más de cuatrocientos libros. ${ }^{32}$ Fue una figura clave en el proceso de intelectualización del arte, el pintor se alza sobre el vulgo y se convierte en humanista de las letras y las artes. Es lógico que una personalidad tan poderosa se proyectase inmediatamente en otros pintores-escritores que se convertirían en sus más fieles discípulos tales como Antonio Mohedano, Juan de Peñalosa y Sandoval (pintor, canónigo y poeta) y Francisco Pacheco. Así se refería éste último en su obra Arte de la Pintura (1649), sobre su preceptor:

"Céspedes peregrino, mi atrevida mano intentó imitar vuestra figura justa empresa, gran bien, alta ventura, si alcanzara la gloria pretendida" ${ }^{33}$

Del ámbito de la escultura destacaré al brillante Alonso Gómez de Sandoval. ${ }^{34}$

Su inventario de bienes constituye todo un ejemplo del lujo, nivel cultural y prestigio social. ${ }^{35}$ Un ingente número de pinturas y una amplia biblioteca son algunos de los elementos más significativos que encontraremos en él.

Mención aparte merecen los plateros que componían un mundo laboral muy diverso.

No podemos asegurar que todos ellos alcanzasen una alta posición socio-económica pero si que se constituyeron como una pequeña elite dentro del mundo artesanal. Un ejemplo sería el del platero cordobés Juan de Olmedo ${ }^{36}$ o el del platero madrileño Antonio León Soto el Viejo. ${ }^{37}$

\footnotetext{
29 Véase: Fortea Pérez, José Ignacio, Córdoba en el siglo XVI: Las Bases demográficas y económicas de una expansión urbana, Publicaciones del Monte de Piedad y Caja de Ahorros de Córdoba, Córdoba, 1981.

30 Nota aclaratoria: Sólo se puede considerar "artes" cuando existe un Colegio de artistas, el resto de oficios deben ser considerados artesanías; aunque ya hemos visto que la propia población de la época apenas distinguía entre ambas categorías.

31 Gómez Moreno, Manuel, "El gran Pablo de Céspedes, pintor y poeta", Boletín de la Real Academia de Córdoba, BRAC, n 59, (1948), pp. 63-68. Nota: Pablo de Céspedes nació en Córdoba hacia el año 1538, estudió junto a Góngora y se codeó con excelsos marianistas como Arias Montano, Ambrosio de Morales, Alderete y otros muchos.

32 AHPCO, Protocolos Notariales, Córdoba, año 1608, Oficio 22, tomo 71, (sin foliar).

33 Zueras Torrens, F, "Los Pintores- Escritores con Céspedes como arquetipo", BRAC, n 95, (1975), pp. 5-23.

34 Nota: Alonso Gómez de Sandoval, escultor nacido en Córdoba en 1713, procedente de los maestros doradores del siglo XVII Gómez Caballero. Fue lego del convento de los trinitarios y allí se formó culturalmente e inició su educación en el arte de la escultura. Posteriormente contrajo matrimonio con Doña Teresa de Góngora.

35 AHPCO, Protocolos Notariales, Córdoba, año 1802, Oficio 26, f. 533-542. Nota: Dicho inventario está descrito por completo en el apéndice documental que incluye este trabajo.

36 AHPCO, Protocolos Notariales, año 1619, Oficio 29, f. 1093 (sigue en el folio 1106).

37 Archivo Histórico Provincial de Madrid, AHPM, año 1623, Prot. 3180, f. 761-767v. Este documento está descrito completamente en el apéndice documental.
} 